\title{
Will the Internet of Things Be Perovskite Powered? Energy Yield Measurement and Real-World Performance of Perovskite Solar Cells in Ambient Light Conditions
}

\author{
Suzanne K. Thomas ${ }^{1}$ (D), Adam Pockett ${ }^{1}$ (D), Krishna Seunarine ${ }^{1,2}$, Michael Spence ${ }^{1}$ (D), Dimitrios Raptis ${ }^{1}$, \\ Simone Meroni ${ }^{1}$ (D), Trystan Watson ${ }^{1}$, Matt Jones ${ }^{2}$ and Matthew J. Carnie ${ }^{1, *(D)}$
}

Citation: Thomas, S.K.; Pockett, A.; Seunarine, K.; Spence, M.; Raptis, D.; Meroni, S.; Watson, T.; Jones, M.; Carnie, M.J. Will the Internet of Things Be Perovskite Powered? Energy Yield Measurement and Real-World Performance of Perovskite Solar Cells in Ambient Light Conditions. IoT 2022, 3 , 109-121. https://doi.org/10.3390/ iot3010006

Academic Editor: Hyun-Ho Choi

Received: 7 December 2021

Accepted: 17 January 2022

Published: 18 January 2022

Publisher's Note: MDPI stays neutral with regard to jurisdictional claims in published maps and institutional affiliations.

Copyright: (C) 2022 by the authors. Licensee MDPI, Basel, Switzerland. This article is an open access article distributed under the terms and conditions of the Creative Commons Attribution (CC BY) license (https:/ / creativecommons.org/licenses/by/ $4.0 /)$.
1 SPECIFIC-IKC and Materials Research Centre, Faculty of Science and Engineering, Swansea University, Swansea SA2 8PP, UK; s.k.thomas@swansea.ac.uk (S.K.T.); adam.pockett@swansea.ac.uk (A.P.); krishna.seunarine@swansea.ac.uk (K.S.); 988717@swansea.ac.uk (M.S.); dimitrios.raptis@Swansea.ac.uk (D.R.); s.m.p.meroni@swansea.ac.uk (S.M.); t.m.watson@swansea.ac.uk (T.W.)

2 Computational Foundry, Faculty of Science and Engineering, Swansea University, Swansea SA2 8PP, UK; matt.jones@Swansea.ac.uk

* Correspondence: m.j.carnie@swansea.ac.uk

\begin{abstract}
The number of interconnected devices, often referred to as the Internet of Things (IoT), is increasing at a considerable rate. It is inevitable therefore that so too will the energy demand. IoT describes a range of technologies such as sensors, software, smart meters, wearable devices, and communication beacons for the purpose of connecting and exchanging data with other devices and systems over the internet. Often not located near a mains supply power source, these devices may be reliant on primary battery cells. To avoid the need to periodically replace these batteries, it makes sense to integrate the technologies with a photovoltaic (PV) cell to harvest ambient light, so that the technologies can be said to be self-powered. Perovskite solar cells have proven extremely efficient in low-light conditions but in the absence of ambient and low-light testing standards, or even a consensus on what is defined by "ambient light", it is difficult to estimate the energy yield of a given PV technology in a given scenario. Ambient light harvesting is complex, subject to spectral considerations, and whether the light source is directly incident on the PV cell. Here, we present a realistic scenario-driven method for measuring the energy yield for a given PV technology in various situations in which an IoT device may be found. Furthermore, we show that laboratory-built p-i-n perovskite devices, for many scenarios, produce energy yields close to that of commercial GaAs solar cells. Finally, we demonstrate an IoT device, powered by a mesoporous carbon perovskite solar module and supercapacitor, and operating through several day-night cycles.
\end{abstract}

Keywords: energy harvesting; photovoltaic; self-powered; perovskite

\section{Introduction}

The rise in connectivity through the Internet of Things (IoT) has led to an increased demand for an efficient, off-grid power supply [1-3]. IoT has the potential to connect billions of devices, ranging from household furnishings to personal electronics such as smart watches and phone $[4,5]$. There are multiple methods of energy harvesting for powering IoT nodes [6] from piezoelectrics, to thermoelectrics [7,8] and hybridised harvesting that utilises two or more of these methods [9,10]. Of all available ambient energy sources, visible light has the greatest power density $[11,12]$ and so photovoltaic (PV) devices are a prime candidate for self-powered IoT nodes, with the added advantage that they can be discretely integrated into the device design [13]. The high cost of commercial devices such as gallium arsenide (GaAs) photovoltaics and the poor performance of commercial silicon photovoltaics in low-light conditions could result in an increased cost and size to devices designed to be cheap and discreet. Therefore, a cost-effective and easily producible cell 
which performs well in low-light conditions is desirable [14]. There have been multiple studies into powering IoT and wireless sensor node networks using photovoltaics, and there are many examples of organic photovoltaics for indoor energy harvesting [15-17]. For example, $20.7 \mu \mathrm{W} / \mathrm{cm}^{2}$ has been achieved under a 300 lux fluorescent light using a PCDTBT:PCBM heterojunction with a PEIE layer to control shunt resistance. Recent studies of the ambient light performance of hybrid lead halide perovskite-based solar cells (PSCs) show that they are a prime candidate for artificial and low-light energy harvesting [18]. Perovskites are direct band gap semiconductors and absorb strongly in the visible spectrum and exhibit a high voltage response at AM 1.5 which implies a minimal intrinsic loss [19], suggesting that PSCs will perform well in low-light conditions [20]. For example, at 1000 lux, power conversion efficiencies (PCEs) of 26.3\% [21], 30.1\% [22], and 35.2\% [23] have been achieved. At lower light intensities (400 lux), 24\% [24], 25.4\% [18], and 26.9\% [25] have been demonstrated.

Standardised testing methods for simulated sunlight have existed since the 1970s with the agreed upon definition of AM 1.5 approved by ASTM in 1982 [26]. At present there are no agreed upon standards for indoor measurements [27]. Some testing methodologies have been suggested such as a regulated charge pump with an integrated optimum power point tracking algorithm specifically designed for indoor solar measurements [28]. A similar methodology to the one presented in this study suggests using historic realistic outdoor intensity/temperature data and measuring the energy yield of PSCs in these conditions [29].

Many of the studies performed for PSCs in low light maintain a constant lux level, generally 200 or 1000 lux [19,21-23,25,30-33], using LED and CFL light sources and direct incident light. These methods are adequate for comparison of materials and interfaces in order to optimise low-light performance but yield little information on how much power these devices might produce in a given scenario. For outdoor solar simulation, the movement of the Sun with respect to the location on Earth and local meteorological conditions are known sufficiently so that simulation software such as $\mathrm{PV}^{*} \mathrm{Sol}$ [34] can accurately predict the energy yield of a particular PV panel over a given period of time. This information is not readily available for predicting ambient light energy-yields as in most cases the lux level is not constant and unlike natural sunlight is less subject to predictable fluctuations, usually due to human factors. For example, at an office desk with natural incident light from a window, the light level will fluctuate during the day while the level of artificial light could be subject to factors such as office occupancy, external weather conditions and whether artificial lights are constantly on or dependant on motion sensors. At end of the working day when artificial lights are turned off, the PV cell must produce enough excess energy to prevent the IoT batteries from draining at night. In order to understand the power output of a particular PV technology in a particular scenario, an understanding of the light power available is necessary. In this study, we have chosen three locations where an IoT device may be deployed and measured the light intensity logged during a number of days. We then recreate a typical day using a customised ambient light simulator and maximum power point tracker (MPPT) to measure power output and energy yield of a particular solar cell technology in one of our chosen scenarios. We show that perovskite solar cells can be competitive with commercial incumbents.

\section{Materials and Methods}

PSCs were fabricated on glass/indium tin oxide (ITO) substrates. Glass/ITO substrates were cleaned by scrubbing with Hellmanex ${ }^{\circledR}$ surfactant $2 \%$ in DI water. Subsequently, substrates were cleaned by ultrasonic bath, heated to 60 degrees, in Hellmanex ${ }^{\circledR}$ solution for $10 \mathrm{~min}$ followed by DI water rinsing and sonication for $2 \mathrm{~min}$, followed by sonication in acetone and the isopropanol solvents for $2 \mathrm{~min}$ each. Finally, substrates were cleaned in $\mathrm{O}_{2}$ plasma for $10 \mathrm{~min}$. For the fabrication of the inverted structure (p-i-n), ITO/NiOx/ $\mathrm{CH}_{3} \mathrm{NH}_{3} \mathrm{PbI}_{3} / \mathrm{PCBM} / \mathrm{BCP} / \mathrm{Ag}$ solar cell devices, a $0.2 \mathrm{M} \mathrm{NiOx}$ solution was prepared by dissolving Nickel acetate tetrahydrate in 2-methoxyethanol at 60 degrees. Once dissolved a small amount of ethanolamine $(12 \mu \mathrm{L} / \mathrm{mL})$ was added to the solution 
before filtration through a $0.45 \mu \mathrm{m}$ PTFE filter. NiOx HTL layer was deposited onto the glass/ITO substrate via single step spin coating at a spin speed of $3000 \mathrm{rpm}$ for $30 \mathrm{~s}$. The NiOx film ( $~ 50 \mathrm{~nm}$ thick) was then annealed at 300 degrees for $30 \mathrm{~min}$. The perovskite solution was prepared by dissolving $605 \mathrm{mg} \mathrm{PbT} 2$ and $199 \mathrm{mg}$ methylammonium iodide in $1 \mathrm{~mL}$ of a 4:1 solvent mix of DMF:DMSO overnight at 60 degrees in the glove box followed by filtration through a $0.45 \mu \mathrm{m}$ PTFE filter. The solution was spin coated onto the HTLs at $4000 \mathrm{rpm}$ for $30 \mathrm{~s}$. After $7 \mathrm{~s}, 200 \mu \mathrm{L}$ of ethyl acetate was deposited directly onto the centre of the rotating sample causing a crystallisation of the perovskite solution into a cohesive film. The perovskite films are then annealed for $10 \mathrm{~min}$ on a 100-degree hotplate to obtain dense black perovskite films of approximately $550 \mathrm{~nm}$ thickness. Next, $20 \mathrm{mg}$ of $[6,6]-$ Phenyl- $\mathrm{C}_{6}$ 0-butyric acid methyl ester (PCBM) was dissolved in $1 \mathrm{~mL}$ of chlorobenzene and heated at 60 degrees overnight in the glove box. The ETL was deposited directly onto the perovskite film via spin coating at $4000 \mathrm{rpm}$ for $30 \mathrm{~s}$, resulting in a film thickness of approximately $200 \mathrm{~nm}$. The sample was allowed to anneal in air before the addition of $100 \mu \mathrm{L}$ of $1 \mathrm{mg} / \mathrm{mL}$ solution of bathocuproine (BCP) in ethanol. The addition of BCP improves the work function compatibility of the ETL to the silver electrodes. Finally, silver electrodes were deposited via thermal evaporation using a bell jar evaporator. Two devices were produced per sample each with an area of $1 \mathrm{~cm}^{2}$. For the n-i-p PSCs ITO/ $\mathrm{SnO}_{2} / \mathrm{CH}_{3} \mathrm{NH}_{3} \mathrm{PBI}_{3} / \mathrm{SPIRO}-\mathrm{OMeTAD} / \mathrm{Au}$ solar cell devices: A solution of $\mathrm{SnO}_{2}$ nanoparticles was prepared by mixing 3.5 parts de-ionised water with 1 part $\mathrm{SnO}_{2}$ nanoparticles $\left(15 \%\right.$ colloidal dispersion in $\mathrm{H}_{2} \mathrm{O}$. The ITO substrate was $\mathrm{O}_{2}$ plasma treated for $10 \mathrm{~min}$ to improve wetting before a layer $(\sim 15 \mathrm{~nm})$ of the $\mathrm{SnO}_{2}$ nanoparticles were deposited onto the ITO via spin coating at $4000 \mathrm{rpm}$ for $30 \mathrm{~s}$. The $\mathrm{SnO}_{2}$ nanoparticle films were then annealed at $140{ }^{\circ} \mathrm{C}$ for $30 \mathrm{~min}$. The perovskite solution was deposited as for the p-i-n devices producing a film $\sim 550 \mathrm{~nm}$ thick. A solution of SPIRO-OMeTAD was prepared by dissolving $90 \mathrm{mg}$ of SPIRO-OMeTAD in $1 \mathrm{ml}$ of chlorobenzene and gently agitating for $10 \mathrm{~min}$. $34 \mu \mathrm{L}$ of 4-tert-butylpyridine (4tBP), $19 \mu \mathrm{L}$ of Lithium bis(trifluoromethanesulfonyl)imide (LiTFSI) [520 mg/mL in acetonitrile], and $10 \mu \mathrm{L}$ of FK209 in acetonitrile were added to dope the solution. The SPIRO-OMeTAD solution was deposited dynamically by spin casting from a height of $1 \mathrm{~cm}$ above the sample surface $10 \mathrm{~s}$ before the $30 \mathrm{~s}$ spin ends, resulting in an $\sim 220 \mathrm{~nm}$ film thickness. Finally, gold electrodes were deposited via thermal evaporation using a bell jar evaporator. Four devices were produced per sample each with an area of $0.16 \mathrm{~cm}^{2}$. For the carbon-based perovskite solar cells: FTO was initially patterned with a $\mathrm{Nb}: \mathrm{YVO}_{4}$ laser $(532 \mathrm{~nm})$. The laser patterned substrate was then cleaned with a solution of Hellmanex ${ }^{\circledR}$ in deionised water, rinsed with acetone, IPA, and finally plasma cleaned in an $\mathrm{O}_{2}$ atmosphere for $5 \mathrm{~min}$. A compact $\mathrm{TiO}_{2}$ BL layer $(50 \mathrm{~nm})$ was deposited by spray pyrolysis with a solution of $10 \%$ Titanium di-isopropoxide bis (acetylacetonate) in IPA on the FTO substrate which kept at $300{ }^{\circ} \mathrm{C}$ on a hot plate. Mesoporous layers of mesoporous $\mathrm{TiO}_{2}(600-800 \mathrm{~nm})$, mesoporous $\mathrm{ZrO}_{2}(1.2-1.5 \mu \mathrm{m})$, and mesoporous carbon $(12-14 \mu \mathrm{m})$ were sequentially screen printed. After each printing the sample was annealed at $550{ }^{\circ} \mathrm{C}$ for Titania, $400{ }^{\circ} \mathrm{C}$ for Zirconia and also $400^{\circ} \mathrm{C}$ for carbon. The paste for the $\mathrm{TiO}_{2}$ layer was diluted in terpineol in a 1:1 ratio by weight. The other pastes were used as bought. The last step of the standard fabrication procedure was the infiltration of perovskite solution. The precursor perovskite solution was synthesised by dissolving 0.439 of $\mathrm{PbI}_{2}, 0.1514$ of MAI and $0.0067 \mathrm{~g}$ of 5-AVAI (to obtain a 3\% molar ratio between 5-AVAI and MAI) in $1 \mathrm{~mL}$ $\gamma$-butyrolactone at $60^{\circ} \mathrm{C} .14 \mu \mathrm{L}$ of the solution drop casted on the $1 \mathrm{~cm}^{2}$ active area of the cells through the carbon layer. Allowing $10 \mathrm{~min}$ time for the solution to percolate throughout the triple stack, the devices were annealed in a fan oven for $1 \mathrm{~h}$. The finished solar cells were then exposed to $70 \%$ relative humidity at $40{ }^{\circ} \mathrm{C} 24 \mathrm{~h}$ to induce a recrystallisation and then dried in a vacuum oven before measuring to reach their final efficiency.

The IoT demonstrator consists of: a STEVAL-ISV021V1 energy harvester and battery charger (STMicroelectronics, Geneva, Switzerland); LS013B7DH03 $128 \times 128$ pixel polymer liquid crystal display (Sharp, Osaka, Japan); BOOSTXL-SHARP128 booster pack (Texas Instruments, Dallas, TX, USA); MSP-EXP430F5529LP microcontroller (Texas Instruments, 
Dallas, TX, USA); SIT15344 ultra-low power oscillator (SITime, Santa Clara, CA, USA); BMP280 Barometric pressure and temperature sensor (Bosch Sensortec, Reutlingen, Germany); TPL5111 ultra-low power system timer (Texas Instruments, Dallas, TX, USA); XBee S1 wireless communication module (Digi International, Hopkins, MN, USA).

\section{Results and Discussion}

In order to measure the energy yield of PSCs in a particular scenario, the available light power, and how it changes during a given day, must also be measured. Three scenarios were chosen, and the light intensity was measured using a logging pyranometer. The spectral response of the data logger is somewhat similar to the human eye, showing a normal distribution in the normalised response from approximately 400 to $700 \mathrm{~nm}$ with a maximum response of approximately $550 \mathrm{~nm}$. In order to account for spectral differences, spectral mismatch calculations are required which will be described in detail later. Ideally, a portable spectrophotometer/spectroradiometer would be used to measure the entire spectral range however, such devices are comparatively expensive and impractical as they require a mains power supply. A simple pendant data logger such as the one used in this work is inexpensive, easy to use, and can be left in situ for up to 6 months $[35,36]$. The lux values were measured by the data logger over the course of several days but for the purpose of comparison, one day for each scenario was chosen. The lux values for the scenarios are shown in Figure 1a below. The first scenario is an open plan office, used by PhD students, where the windows face onto a covered walkway and so has very little natural light. The lighting within this room is solely from LED lighting with very little variance throughout the day. The light intensity during the day (06:00-20:00) remains consistent at approximately 150 lux. The lights in the office are switched on using a motion sensor, and so when not occupied, all office lights are switched off and the lux level drops to zero. The second scenario is another open plan office, used by postdoctoral researchers. The office has east faced windows, so has natural light which is typically brighter during the early morning. The office also has LED lighting. The maximum illuminance in this scenario peaks at approximately 09:00 at approximately 350 lux. From midday onward the illuminance is fairly consistent at approximately 200 lux. The third scenario is a covered walkway with a white translucent canopy approximately $5 \mathrm{~m}$ above the measurement point. There is some LED artificial lighting but most of the light here is highly diffuse natural light shining through the canopy. This scenario has the most variance in illuminance with a maximum value of approximately 3000 lux at midday. The light intensity in this scenario shows the most variance and this can be attribute to the meteorological conditions in South Wales being variable and often cloudy. It should be noted the illuminance measurements were taken in positions where an IoT might be typically found, i.e., fixed to wall in some location and not subject to direct incident light. These values, particularly the office-based scenarios, correspond to the standard BS EN 12464-1:2021 (Light and lighting. Lighting of work places), which stipulated that "maintained illuminance on walls" ( $\left.\bar{E}_{m, \text { wall }}\right)$ should be 100-150 lux dependant on the task (e.g., typing, filing, and data processing) [37].

Three types of PSC were tested (see schematics in Figure 2): a mesoporous carbonbased perovskite solar cell (cPSC), an inverted p-i-n PSC with NiO and PCBM transport layers, and an n-i-p PSC with $\mathrm{SnO}_{2}$ and Spiro-OMeTAD transport layers. These "in-house" laboratory-built PSCs were compared to commercial GaAs and a-Si solar cells. All cells were measured under AM1.5 standard lighting, often termed "1-Sun". Table 1 below outlines the main performance parameters of each cell at 1-Sun. As might be expected the commercial GaAs cell is the most efficient followed by the n-i-p PSC and the cPSC. The poor performance of the $\mathrm{p}-\mathrm{i}-\mathrm{n}$ perovskite cell can be attributed to the cell area and the resultant series resistance increase due to the relatively larger cell area. The high series resistance results in a low fill-factor and hence a lower calculated efficiency. Ideally, all cells tested would have the same cell area but as all cells were sourced from different providers, this is difficult to achieve. The size of the device can have a critical influence on device physics, most importantly the series resistance of the cell increases with increasing size. 
This is less critical at low light intensities, however, as the carrier densities are at such a level that series resistance is much less of a limiting factor.

a)

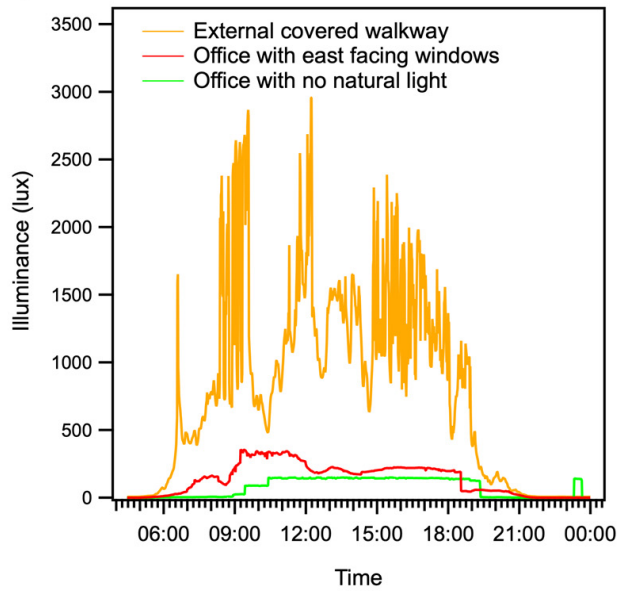

b)

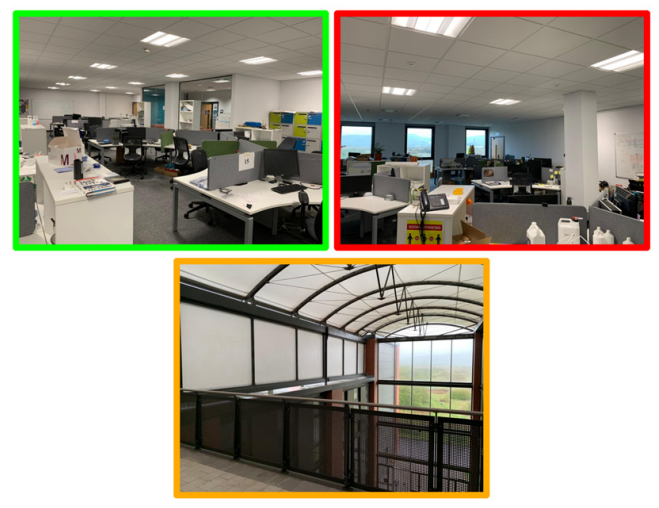

Figure 1. (a) Light intensity measurements from three scenarios, and (b) scenario locations pictured clockwise from top left: scenario one (office with no natural light), scenario two (office with east facing windows) and scenario three (external, covered walkway).

a)
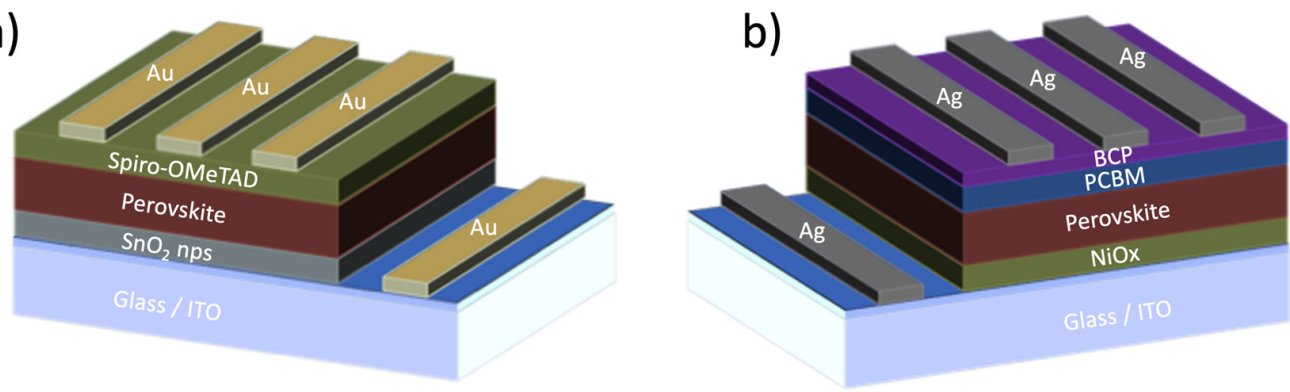

c)



Figure 2. Schematic diagrams of the three perovskite solar cell (PSC) architectures tested. Clockwise from top-left, (a) n-i-p PSC, (b) p-i-n PSC and (c) carbon PSC. The layer thicknesses are not to scale. See Section 2 for typical layer thicknesses.

Table 1. Solar cell parameters measured at 1 sun (AM1.5).

\begin{tabular}{ccccccc}
\hline Device & $\mathbf{V}_{\text {OC }}(\mathbf{V})$ & $\mathbf{J S C}_{\text {SC }}\left(\mathbf{m A} / \mathbf{c m}^{\mathbf{2}}\right)$ & FF & Area $\left(\mathbf{c m}^{\mathbf{2}}\right)$ & $\mathbf{P}_{\text {MAX }}\left(\mathbf{m W} / \mathbf{c m}^{\mathbf{2}}\right)$ & PCE $(\%)$ \\
\hline p-i-n PSC & 0.993 & 20.1 & 0.35 & 1 & 7.0 & 7.0 \\
n-i-p PSC & 1.123 & 19.9 & 0.72 & 0.16 & 16.1 & 16.1 \\
c-PSC & 0.878 & 22.2 & 0.58 & 0.5 & 11.3 & 11.3 \\
a-Si & 3.399 & 0.54 & 0.22 & 13 & 0.4 & 0.4 \\
GaAs & 1.112 & 26.9 & 0.80 & 8.5 & 23.9 & 23.9 \\
\hline
\end{tabular}


To measure the energy yield of the PSCs in each of the scenarios, a customised ambient light simulator with maximum power point tracking (MPPT) was used to recreate the time-dependent light intensity data so that any given period of time could be simulated, and the PSCs tested under those conditions. It should be noted that MPPT in this case refers to the measurement of the maximum power point only and not the technique used to maximise energy extraction. As such, the system employed for these experiments utilises a modified perturb and observe $(\mathrm{P} \& \mathrm{O})$ algorithm. A standard $\mathrm{P} \& \mathrm{O}$ algorithm maximises the power output by constantly perturbing the operating voltage and recording the effect on the power output, the algorithm is modified by the inclusion of an arbitrarily defined power inversion threshold to mitigate high hysteresis of PSCs and eliminate non-optimal power tracking [38]. MPPT data was taken at 1 point per second over the course of the whole scenario. The ambient light solar simulator uses LEDs of $2700 \mathrm{~K}$ colour temperature fitted with a diffuser to be more realistic, as our measurements of scenario-based light intensity were never taken in direct incident light. Because the LEDs in the MPPT system have a different output spectrum to light sources in our scenarios, spectral mismatch calculations are required in order to accurately measure the energy yield of our devices.

When considering solar cells for the outdoors, one must only consider a single source of light, the Sun, of which the spectral characteristics and angle of elevation are known sufficiently so that accurate predictions of light power can be calculated for a given location on the planet. Ambient lighting is far more complex than sunlight as most indoor environments have a mixture of artificial light sources as well as incident and diffuse natural light provided by windows which could be of several aspects. The characteristics of indoor lighting are highly dependent on room occupancy, personal preference and seasonal and daily variance in the amount of available natural light. In standard solar cell testing procedures, a calibrated reference cell is used to adjust the intensity of an indoor solar simulator (AM 1.5G) which is then used for testing unknown solar cells. It is often the case that the reference cell and unknown cell will exhibit different spectral responses under the same conditions leading to an error known as the spectral mismatch error $[39,40]$. In order to correct for this a spectral mismatch factor (MMF), Equation (1) must be calculated [41].

$$
\operatorname{MFF}=\frac{\int E_{\text {ref }}(\lambda) \operatorname{SR}_{\text {ref }}(\lambda) d \lambda \int E_{\text {meas }}(\lambda) \operatorname{SR}_{\text {sample }}(\lambda) d \lambda}{\int E_{\text {meas }}(\lambda) \operatorname{SR}_{\text {ref }}(\lambda) d \lambda \int E_{\text {ref }}(\lambda) \operatorname{SR}_{\text {sample }}(\lambda) d \lambda}
$$

where $E_{\text {ref }}$ and $E_{\text {meas }}$ are the spectral irradiance of the sun and AM 1.5G, respectively, and $\mathrm{SR}_{\text {ref }}$ and $\mathrm{SR}_{\text {sample }}$ are the spectral response of the reference and test cell, respectively.

In the case of our experiments, a non-conventional approach to simulated testing is taken. The reference spectra, $\mathrm{E}_{\text {ref }}$, is replaced by the spectra of the scenario in which each data set was obtained, i.e., an office or corridor. The spectral irradiance distribution of the solar simulator, $\mathrm{E}_{\text {meas, }}$ is replaced by the spectra of the LED array of MPPT system. When the spectral response of the test cell is different from that of the reference cell, then a mismatch factor must be calculated. The spectral response or external quantum efficiency (EQE) for the a-Si, GaAs, and PSCs was obtained and can be seen in Figure 3. Since the same perovskite absorber is used in all PSCs, the normalised EQE is expected to be the same for the purposes of the spectral mismatch calculation. The measured power output of each solar cell is then multiplied by the mismatch factor corresponding to the scenario. The calculated MFFs for each scenario and PV device are shown in Table 2 below.

Table 2. Solar cell parameters measured at 1 sun (AM1.5).

\begin{tabular}{cccc}
\hline & Perovskite MMF & GaAs MMF & a-Si MMF \\
\hline Scenarios one and two & 0.99 & 1.02 & 0.90 \\
Scenario three & 0.64 & 0.60 & 0.73 \\
\hline
\end{tabular}



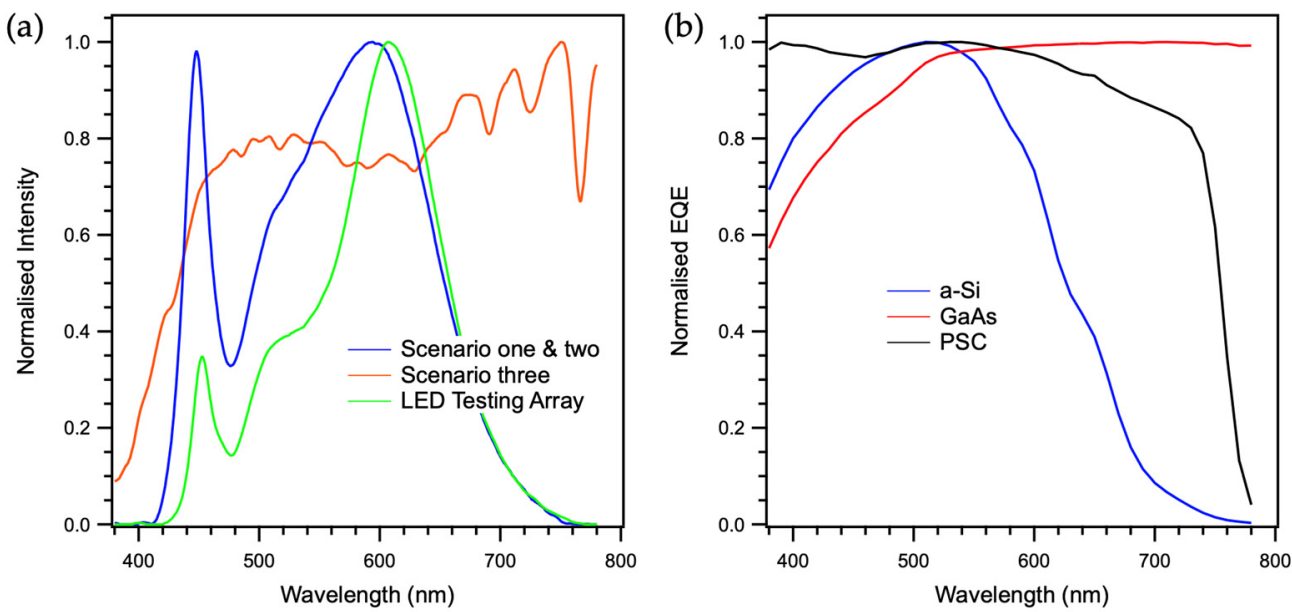

Figure 3. (a) Normalised light emission spectra for scenarios one and three at midday and (b) normalised external quantum efficiency (the spectral response) of a-Si, GaAs and PSC technologies. Note, all PSCs have similar EQE as even though device architecture differs, the absorber is the same in each case.

Figure 4 below shows the real-time power output and calculated energy yield for each of the test devices in each of the scenarios for one typical day. Daytime MPPT data is only shown, and used for calculation of energy yield, as during the night, the lux values are effectively zero, and hence the night-time power output of the cells, was zero. Figure 4a shows the power output and energy yield for the photovoltaics cells in scenario one ( $\mathrm{PhD}$ Office). This is the lowest illumination scenario as there is no natural lighting. The luminance in this scenario never reaches beyond 200 lux. The best performing cell in this case is the GaAs cell, which has an energy yield of $0.163 \mathrm{mWhr} \mathrm{cm}^{-2}$. This is followed closely by the $1 \mathrm{~cm}^{2} \mathrm{p}-\mathrm{i}-\mathrm{n}$ PSC with $0.136 \mathrm{mWhr} \mathrm{cm}^{-2}$. The n-i-p PSC has a much lower energy yield, $0.039 \mathrm{mWhr} \mathrm{cm}{ }^{-2}$, lower than the a-Si cell at $0.050 \mathrm{mWhr} \mathrm{cm}^{-2}$. This is perhaps at first a surprising result given the values at one-sun light intensity reported in Table 1. However, the factors that influence device operation can be different in different light-intesity regimes. For example, the poorer performance of the $1 \mathrm{~cm}^{2} \mathrm{p}$-i-n perovskite cell at one-sun compared to the $0.16 \mathrm{~cm}^{2} \mathrm{n}$-i-p PSC can be attributed, in part, to an increased series resistance because generated carriers have further to travel in order to be extracted at the cell electrode. Low light intensities result in fewer generated carriers, meaning that series resistance is no longer a limiting factor. However, at low light intensities, the shunt resistance becomes more important and higher shunt resistances are associated with defect free semi-conductor layers. The $1 \mathrm{~cm}^{2} \mathrm{p}$-i-n cell clearly has high shunt resistance, whereas the $0.16 \mathrm{~cm}^{2} \mathrm{n}$-i-p cell seems to have shunting issues (possibly due to pinholes). Despite this result, it is encouraging nonetheless that a perovskite cell, manufactured in laboratory conditions, and with obvious series resistance limitations at high light intensity can perform almost as well as a commercial GaAs at low light intensities. The median scenario in terms of light intensity is scenario two (postdoctoral office), which has east facing windows. The aspect of the windows results in a higher light intensity in the morning compared to the afternoon. Nonetheless the light intensity barely reaches above 500 lux. Again, the GaAs cell is the best performing, with an energy yield of $0.327 \mathrm{mWhr} \mathrm{cm}^{-2}$. It can also be observed that during periods of higher light intensity, the n-i-p and p-i-n PSCs have similar performance, and it is only in the afternoon, when light intensity reduces, that the $\mathrm{p}$-i-n cell performance begins to increase comparatively to the n-i-p cell, resulting in a higher energy yield for the p-i-n cell $\left(0.139 \mathrm{mWhr} \mathrm{cm}^{-2}\right)$ compared to the n-i-p cell $\left(0.114 \mathrm{mWhr} \mathrm{cm}{ }^{-2}\right)$. The third scenario has the highest overall light intensity, and the greatest variance in light intensity and again the GaAs cell is the best performing at $1.25 \mathrm{mWhr} \mathrm{cm}^{-2}$. The $\mathrm{p}$-i-n cell has the second-best performance $\left(0.92 \mathrm{mWhr} \mathrm{cm}^{-2}\right)$, despite the measurement showing a drop-out between 07:00 and 08:00. The drop-out in the measurement shows how 
susceptible lab-built cells can be to electrical stability in relation to MPPT measurement and unfortunately the measurement could not be repeated due to degradation of the p-i-n cell. The cause of the power drop-outs cannot be fully explained at present. They could be caused by environmental instability and the migration of mobile ions, giving rise to electrical instability. The P\&O algorithm used by the MPPT to calculate the maximum power point does not cope well with the variable power output of PSCs and it could be that the drop-out is not as severe as the data suggests, but because the system could not obtain a stable measurement at that point in time it is recorded as zero. The n-i-p cell has an energy yield in scenario three of $0.49 \mathrm{mWhr} \mathrm{cm}^{-2}$ and despite appearing to have a similar power output to the $\mathrm{p}-\mathrm{i}-\mathrm{n}$ cell earlier in the measurement, performs poorly in comparison later in the measurement so that the energy yield is significantly lower than the $\mathrm{p}-\mathrm{i}-\mathrm{n}$ cell. The reason for this is unclear but it may be due to degradation of the perovskite absorber layer.

The a-Si and cPSC cells have not so far been discussed in relation to the scenarios. Amorphous silicon solar cells are relatively cheap to produce and have been used in low power electronics such as pocket calculators for decades but are relatively inefficient at higher light intensities. It is encouraging to observe that in all cases, the energy yield of the p-i-n PSC is higher than the a-Si cell and at higher light intensities the n-i-p and the cPSCs also show better energy yields. cPSCs show better performance than the a-Si cells during I-V measurement at one-sun (Table 1) and indeed in scenario three the PSC tested has a greater energy yield. However, in scenarios one and two which have on average lower light intensities the cPSC energy yields are lower than that of the a-Si. To explain why this might be the case the time dependant response of the CPSC I-V curve under 1000 lux is shown in Figure 5 where it can be observed that it takes over 10 min of light soaking for the I-V curve to stabilise. We have previously attributed this slow light-soaking response to the link between surface recombination and ionic movement [42] and propose that in realistic low-light scenarios, the fluctuations in light intensities mean that the cPSCs never reach a stabilised state and therefore never reach a point of optimised performance. The slightly higher light intensities experienced in scenario three create a greater driving force for ion reorganisation and hence stabilisation and so the cPSC outperforms a-Si once the light intensity is sufficient to stabilise the cPSC output.

Despite the poorer performance in terms of energy yield, cPSC do have one advantage over the other thin-film PSCs. cPSCs are far more environmentally stable, generally operating for several months without significant degradation. Thin-film PSCs, despite their higher efficiencies, are prone to degrade rapidly if not appropriately encapsulated. It is for this reason that cPSCs were chosen to build our IoT demonstrator to evaluate cPSCs as energy harvester power sources for IoT devices. Our proof-of-concept IoT device measures room temperature (in ${ }^{\circ} \mathrm{C}$ ) and atmospheric pressure (in mbar) every $20 \mathrm{~min}$. The data obtained by the IoT device is then transmitted to a remote receiving station every $6.5 \mathrm{~h}$. The sensors of the IoT device are connected to an ultra-low power micro-controller, which is powered by a supercapacitor $(3 \mathrm{~V}, 10 \mathrm{~F})$. The energy harvester, a cPSC mini module (6 cells connected in series, $1.95 \mathrm{~cm}^{2}$ ), is used to charge the supercapacitor via an energy harvesting module. The system was placed in a laboratory where the average light intensity was 800 lux. The charging and discharging of the supercapacitor by the cPSC mini module were monitored over the course of three days. The results of which are shown in Figure 6 despite the cPSC apparently dropping out periodically. It can be observed that the cPSC sufficiently recharges the supercapacitor after its discharge overnight, meaning that the IoT device is self-powering.

Using the data collected from our IoT device, we can it is possible to calculate the amount of charge $(Q)$ gained by the supercapacitor during the day vs. that lost during the night-time. From the logged data shown in Figure 6, the minima and maxima supercapacitor voltages are as follows: 2.952, 3.052, 2.953, 3.069, 2.976, and 3.088 V. The capacitance $(C)$ of the supercapacitor is $10 \mathrm{~F}$ and so using $Q=C V$, it is possible to calculate an average charge received $\left(Q_{\text {day }}\right)$ of 1.094 coulombs vs. an average discharge $\left(Q_{\text {night }}\right)$ of 0.958 coulombs meaning that this device should be self-powering for as long as the 
conditions in the laboratory remained unchanged and as long as the cPSC lasts before degradation detriments performance.


Figure 4. MPP (solid line) and energy yield (dashed line) for a single day from each scenario: (a) office with no natural light, (b) office with east facing window, and (c) covered external walkway. 




Figure 5. I-V curve showing response of cPSC to continuous illumination over ten minutes at 1000 lux.

a)

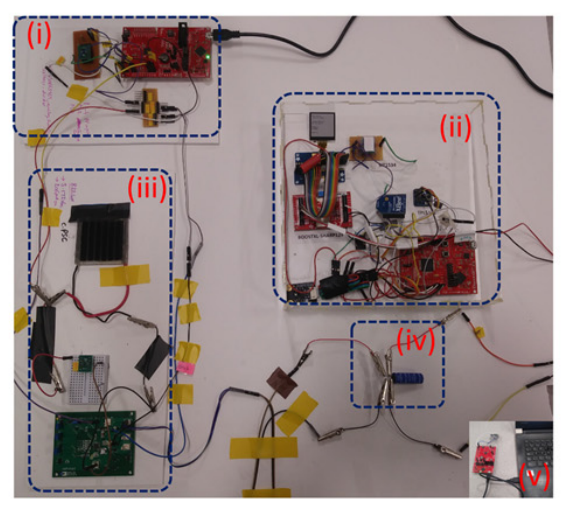

b)

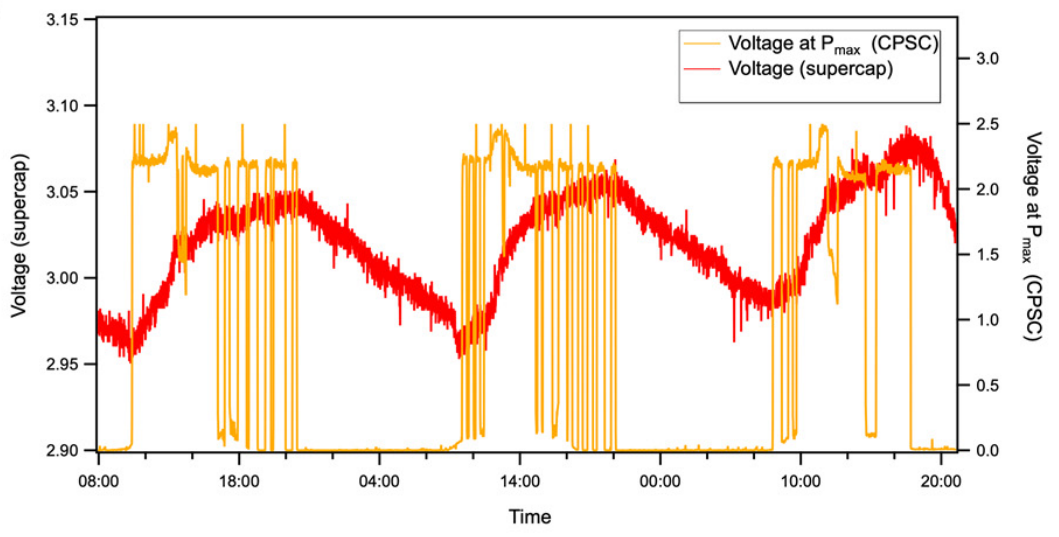

Figure 6. (a) Development board layout of the cPSC powered IoT device where (i) is a data logger, (ii) is an ultra-low power atmospheric pressure and temperature sensor with XBee communication module, (iii) is the CPSC module and MPPT circuit, (iv) is the super-capacitor for storing harvested ambient light energy, and (v) is the remote receiving XBee module and microcontroller; (b) the voltage of the IoT device supercapacitor measured over three day/night cycles (red) and the voltage at MPP of the perovskite solar cell.

\section{Conclusions}

Perovskite solar cells are a relatively new photovoltaic technology but have already proven themselves as efficient low-light energy harvesters. In this work, we developed a scenario-based approach to evaluate the performance of laboratory-built perovskite solar cells vs. that of commercial state-of-the-art technologies. Our work has shown that our perovskite solar cells can suffer from low shunt resistance at low light intensity and carbon perovskite solar cells, in particular, suffer from a slow response to changing light-intensity. Perovskite solar cells can suffer from poor environmental stability and as shown in this work, poor electrical stability. Despite these issues, laboratory-built p-i-n PSCs perform almost as well as state-of-the-art GaAs cells. We believe most of the issues related to low shunt resistance and electrical instability are caused by a lack of manufacturing optimisation 
in the laboratory and should PSCs be developed commercially, most of these drawbacks can be eliminated by consistency in fabrication producing pin-hole free layers. GaAs PV cells use expensive materials and processes, whereas perovskites use much cheaper precursors and simple low-temperature manufacturing techniques so could potentially have a much lower production cost per watt generated. Finally, to prove that PSCs could power the internet-of-things, we built a simple device powered consisting of sensors and communication beacons and we demonstrated that it produces more power than it consumes, proving that perovskite solar cells are a potential power source for self-powered IoT devices.

Author Contributions: Conceptualisation, M.J.C. and A.P.; methodology, M.J.C. and A.P.; formal analysis, M.J.C., S.K.T. and A.P.; investigation, S.K.T. and K.S.; resources, T.W., S.M., M.S., K.S. and D.R.; data curation, S.K.T.; writing — original draft preparation, S.K.T.; writing-review and editing, M.J.C. and A.P.; supervision, M.J.C., T.W. and M.J.; project administration, M.J.C. and M.J.; funding acquisition, M.J. All authors have read and agreed to the published version of the manuscript.

Funding: This work was funded by the Engineering and Physical Sciences Research Council (EPSRC): SPECIFIC-IKC (EP/N020863/1), PV-Interfaces (EP/R032750/1), and ATIP (EP/T028513/1). It was also funded by the European Regional Development Fund (ERDF): SPARC II.

Data Availability Statement: All data created during this research are openly available from the Swansea University data archive at: https://doi.org/10.5281/zenodo.5764768 (accessed on 6 December 2021).

Conflicts of Interest: The authors declare no conflict of interest.

\section{References}

1. Sammonds, C. The Internet of Things Will Depend on Sustainable Energy. Available online: https://medium.com/primalbase/ the-internet-of-things-will-depend-on-sustainable-energy-65b10815a925 (accessed on 21 October 2021).

2. Lueth, K.L. IoT 2019 in Review: The 10 Most Relevant IoT Developments of the Year. IoT Analytics, January 2020. Available online: https:/ / iot-analytics.com/iot-2019-in-review / (accessed on 6 December 2021).

3. Matheson, R. Photovoltaic-Powered Sensors for the "Internet of Things". MIT News, September 2019. Available online: https: //news.mit.edu/2019/photovoltaic-rfid-sensors-iot-0927 (accessed on 6 December 2021).

4. Overview of the Most Popular Smart Home Devices. IoTLineup.Com. 2021. Available online: http:/ / iotlineup.com (accessed on 6 December 2021).

5. Ornes, S. Core Concept: The Internet of Things and the Explosion of Interconnectivity. Proc. Natl. Acad. Sci. USA 2016, 113, 11059-11060. [CrossRef]

6. Eltresy, N.A.; Dardeer, O.M.; Al-Habal, A.; Elhariri, E.; Hassan, A.H.; Khattab, A.; Elsheakh, D.N.; Taie, S.A.; Mostafa, H.; Elsadek, H.A.; et al. RF Energy Harvesting IoT System for Museum Ambience Control with Deep Learning. Sensors 2019, $19,4465$. [CrossRef]

7. Ali, Q.I. Design \& Implementation of a Mobile Phone Charging System Based on Solar Energy Harvesting. In Proceedings of the 2010 1st International Conference on Energy, Power and Control (EPC-IQ), Basrah, Iraq, 30 November-2 December 2010; pp. 264-267.

8. Vullers, R.J.M.; van Schaijk, R.; Doms, I.; van Hoof, C.; Mertens, R. Micropower Energy Harvesting. Solid-State Electron. 2009, 53, 684-693. [CrossRef]

9. Zhang, Y.; Shen, S.; Chiu, C.Y.; Murch, R. Hybrid RF-Solar Energy Harvesting Systems Utilizing Transparent Multiport Micromeshed Antennas. IEEE Trans. Microw. Theory Tech. 2019, 67, 4534-4546. [CrossRef]

10. Tan, Y.K.; Panda, S.K. Energy Harvesting From Hybrid Indoor Ambient Light and Thermal Energy Sources for Enhanced Performance of Wireless Sensor Nodes. IEEE Trans. Ind. Electron. 2011, 58, 4424-4435. [CrossRef]

11. Cao, S.; Li, J. A Survey on Ambient Energy Sources and Harvesting Methods for Structural Health Monitoring Applications. Adv. Mech. Eng. 2017, 9, 1687814017696210. [CrossRef]

12. de Mil, P.; Jooris, B.; Tytgat, L.; Catteeuw, R.; Moerman, I.; Demeester, P.; Kamerman, A. Design and Implementation of a Generic Energy-Harvesting Framework Applied to the Evaluation of a Large-Scale Electronic Shelf-Labeling Wireless Sensor Network. EURASIP J. Wirel. Commun. Netw. 2010, 2010, 343690. [CrossRef]

13. Sahraei, N.; Looney, E.E.; Watson, S.M.; Peters, I.M.; Buonassisi, T. Adaptive Power Consumption Improves the Reliability of Solar-Powered Devices for Internet of Things. Appl. Energy 2018, 224, 322-329. [CrossRef]

14. Chirap, A.; Popa, V.; Coca, E.; Potorac, D.A. A Study on Light Energy Harvesting from Indoor Environment: The Autonomous Sensor Nodes. In Proceedings of the 2014 International Conference on Development and Application Systems (DAS), Suceava, Romania, 15-17 May 2014; pp. 127-131. [CrossRef] 
15. Lechêne, B.P.; Cowell, M.; Pierre, A.; Evans, J.W.; Wright, P.K.; Arias, A.C. Organic Solar Cells and Fully Printed Super-Capacitors Optimized for Indoor Light Energy Harvesting. Nano Energy 2016, 26, 631-640. [CrossRef]

16. Aoki, Y. Photovoltaic Performance of Organic Photovoltaics for Indoor Energy Harvester. Org. Electron. 2017, 48, 194-197. [CrossRef]

17. Steim, R.; Ameri, T.; Schilinsky, P.; Waldauf, C.; Dennler, G.; Scharber, M.; Brabec, C.J. Organic Photovoltaics for Low Light Applications. Sol. Energy Mater. Sol. Cells 2011, 95, 3256-3261. [CrossRef]

18. di Giacomo, F.; Zardetto, V.; Lucarelli, G.; Cinà, L.; di Carlo, A.; Creatore, M.; Brown, T.M. Mesoporous Perovskite Solar Cells and the Role of Nanoscale Compact Layers for Remarkable All-Round High Efficiency under Both Indoor and Outdoor Illumination. Nano Energy 2016, 30, 460-469. [CrossRef]

19. Juang, S.S.-Y.; Lin, P.-Y.; Lin, Y.-C.; Chen, Y.-S.; Shen, P.-S.; Guo, Y.-L.; Wu, Y.-C.; Chen, P. Energy Harvesting Under Dim-Light Condition With Dye-Sensitized and Perovskite Solar Cells. Front. Chem. 2019, 7, 209. [CrossRef]

20. Dong, S.; Valerio, A.; Riccardo, C.; Mingjian, Y.; Erkki, A.; Andrei, B.; Yin, C.; Sjoerd, H.; Alexander, R.; Khabiboulakh, K.; et al. Low Trap-State Density and Long Carrier Diffusion in Organolead Trihalide Perovskite Single Crystals. Science 2015, 347, 519-522. [CrossRef]

21. Chen, C.-Y.; Chang, J.-H.; Chiang, K.-M.; Lin, H.-L.; Hsiao, S.-Y.; Lin, H.-W. Perovskite Photovoltaics for Dim-Light Applications. Adv. Funct. Mater. 2015, 25, 7064-7070. [CrossRef]

22. Chen, C.-Y.; Lee, W.-H.; Hsiao, S.-Y.; Tsai, W.-L.; Yang, L.; Lin, H.-L.; Chou, H.-J.; Lin, H.-W. Vacuum-Deposited Perovskite Photovoltaics for Highly Efficient Environmental Light Energy Harvesting. J. Mater. Chem. A 2019, 7, 3612-3617. [CrossRef]

23. Li, M.; Zhao, C.; Wang, Z.-K.; Zhang, C.-C.; Lee, H.K.H.; Pockett, A.; Barbé, J.; Tsoi, W.C.; Yang, Y.-G.; Carnie, M.J.; et al. Interface Modification by Ionic Liquid: A Promising Candidate for Indoor Light Harvesting and Stability Improvement of Planar Perovskite Solar Cells. Adv. Energy Mater. 2018, 8, 1801509. [CrossRef]

24. Lucarelli, G.; di Giacomo, F.; Zardetto, V.; Creatore, M.; Brown, T.M. Efficient Light Harvesting from Flexible Perovskite Solar Cells under Indoor White Light-Emitting Diode Illumination. Nano Res. 2017, 10, 2130-2145. [CrossRef]

25. Dagar, J.; Castro-Hermosa, S.; Lucarelli, G.; Cacialli, F.; Brown, T.M. Highly Efficient Perovskite Solar Cells for Light Harvesting under Indoor Illumination via Solution Processed SnO2/MgO Composite Electron Transport Layers. Nano Energy 2018, 49, 290-299. [CrossRef]

26. Gueymard, C.A.; Myers, D.; Emery, K. Proposed Reference Irradiance Spectra for Solar Energy Systems Testing. Sol. Energy 2002, 73, 443-467. [CrossRef]

27. Minnaert, B.; Veelaert, P. A Proposal for Typical Artificial Light Sources for the Characterization of Indoor Photovoltaic Applications. Energies 2014, 7, 1500-1516. [CrossRef]

28. Kim, J.; Kim, J.; Kim, C. A Regulated Charge Pump With a Low-Power Integrated Optimum Power Point Tracking Algorithm for Indoor Solar Energy Harvesting. IEEE Trans. Circuits Syst. II Express Briefs 2011, 58, 802-806. [CrossRef]

29. Tress, W.; Domanski, K.; Carlsen, B.; Agarwalla, A.; Alharbi, E.A.; Graetzel, M.; Hagfeldt, A. Performance of Perovskite Solar Cells under Simulated Temperature-Illumination Real-World Operating Conditions. Nat. Energy 2019, 4, 568-574. [CrossRef]

30. Raifuku, I.; Ishikawa, Y.; Uraoka, Y.; Ito, S. Potential of Perovskite Solar Cells for Power Sources of IoT Applications. In Proceedings of the 2016 IEEE International Meeting for Future of Electron Devices, Kansai (IMFEDK), Kyoto, Japan, 23-24 June 2016; pp. 1-2. [CrossRef]

31. de Rossi, F.; Pontecorvo, T.; Brown, T.M. Characterization of Photovoltaic Devices for Indoor Light Harvesting and Customization of Flexible Dye Solar Cells to Deliver Superior Efficiency under Artificial Lighting. Appl. Energy 2015, 156, 413-422. [CrossRef]

32. Lee, H.K.H.; Barbé, J.; Meroni, S.M.P.; Du, T.; Lin, C.-T.; Pockett, A.; Troughton, J.; Jain, S.M.; de Rossi, F.; Baker, J.; et al. Outstanding Indoor Performance of Perovskite Photovoltaic Cells-Effect of Device Architectures and Interlayers. Sol. RRL 2019, 3, 1800207. [CrossRef]

33. Ann, M.H.; Kim, J.; Kim, M.; Alosaimi, G.; Kim, D.; Ha, N.Y.; Seidel, J.; Park, N.; Yun, J.S.; Kim, J.H. Device Design Rules and Operation Principles of High-Power Perovskite Solar Cells for Indoor Applications. Nano Energy 2020, 68, 104321. [CrossRef]

34. The Solar Design Company. Available online: https://www.solardesign.co.uk/index.php (accessed on 21 October 2021).

35. ONSET. Onset Data Loggers. Available online: https://www.onsetcomp.com/products/data-loggers/mx2202 (accessed on 21 October 2021).

36. Long, M.H.; Rheuban, J.E.; Berg, P.; Zieman, J.C. A Comparison and Correction of Light Intensity Loggers to Photosynthetically Active Radiation Sensors. Limnol. Oceanogr. Methods 2012, 10, 416-424. [CrossRef]

37. Britsh Standards Institute. BS EN 12464-1:202; Light and Lighting. Lighting of Work Places-Indoor Work Places. BSI Group: London, UK, 2021.

38. Pellet, N.; Giordano, F.; Ibrahim Dar, M.; Gregori, G.; Zakeeruddin, S.M.; Maier, J.; Grätzel, M. Hill Climbing Hysteresis of Perovskite-Based Solar Cells: A Maximum Power Point Tracking Investigation. Prog. Photovolt. Res. Appl. 2017, 25, 942-950. [CrossRef]

39. Müllejans, H.; Ioannides, A.; Kenny, R.; Zaaiman, W.; Ossenbrink, H.A.; Dunlop, E.D. Spectral Mismatch in Calibration of Photovoltaic Reference Devices by Global Sunlight Method. Meas. Sci. Technol. 2005, 16, 1250-1254. [CrossRef]

40. Bliss, M.; Smith, A.; Betts, T.R.; Baker, J.; de Rossi, F.; Bai, S.; Watson, T.; Snaith, H.; Gottschalg, R. Spectral Response Measurements of Perovskite Solar Cells. IEEE J. Photovolt. 2019, 9, 220-226. [CrossRef] 
41. Bentham. Calculation of Spectral Mismatch. Available online: https://www.bentham.co.uk/knowledge/tools-resources/ application-guides/calculation-of-spectral-mismatch-163/ (accessed on 22 October 2021).

42. Pockett, A.; Raptis, D.; Meroni, S.M.P.; Baker, J.; Watson, T.; Carnie, M. Origin of Exceptionally Slow Light Soaking Effect in Mesoporous Carbon Perovskite Solar Cells with AVA Additive. J. Phys. Chem. C 2019, 123, 11414-11421. [CrossRef] 